\title{
Characterization of Correlation between Microstructure and Fracture Properties of Poly(lactic acid) Polymer Blends"
}

\author{
Tetsuo TAKAYAMA ${ }^{* *}$ and Mitsugu TODO ${ }^{* * *}$ \\ **Interdisciplinary Graduate School of Engineering Sciences, Kyushu University, \\ 6-1 Kasuga-koen, Kasuga 816-8580, Japan \\ E-mail: takayama@riam.kyushu-u.ac.jp \\ ${ }^{* * *}$ Research Institute for Applied Mechanics, Kyushu University, \\ 6-1 Kasuga-koen, Kasuga 816-8580, Japan \\ E-mail: todo@riam.kyushu-u.ac.jp
}

\begin{abstract}
Lysine tri-isocyanate (LTI) was added to a biodegradable polymer blend of poly(lactic acid) (PLA) and poly ( $\varepsilon$-caprolacton) (PCL) under melt-mixing condition in order to improve the miscibility of PLA and PCL. It was found that the mode I fracture energy of the polymer blend effectively increases with increase of LTI content. Microscopic examination also showed that the size of PCL phase decreases due to LTI addition, leading to the reduction of void formation and suppression of local stress concentration, thus the improvement of the fracture energy. The improved miscibility also contributes to the ductility enhancement, which further increases the fracture energy.
\end{abstract}

Key words: Polymer Blend, Biodegradable Polymer, Fracture Energy, Fracture Mechanism, Ductile Fracture

\section{Introduction}

Considerable attention has been paid to biodegradable polymers in recent years, mainly due to the increasing interests in the preservation of environment by substitution for the petrochemical polymers. Poly (lactic acid) (PLA) is one of the typical biodegradable polymers, which has been considered for the use in a variety of industrial fields, including automobile, computer and electric appliances. PLA has also been used as an implant biomaterial in medical fields such as orthopedics and oral surgery [1,2]. Its importance has led to many studies on its mechanical properties and fracture behavior [3-7] which found that the fracture behavior of PLA is relatively brittle in nature. Therefore, blending with ductile biodegradable polymers such as poly ( $\varepsilon$-caprolacton) (PCL) has been adopted to improve the fracture properties [8-14]. Although PCL blend increases the fracture energy of neat PLA, it was also found that the polymer blend exhibits phase separation as a result of the immiscibility of the polymers [9]. Lysine tri-isocyanate (LTI) was recently discovered to be able to effectively improve such immiscibility [15-18]; however, details of the fracture property and the associated mechanisms are yet to be well understood.

In this study, therefore, blends of PLA/PCL and PLA/PCL/LTI with different LTI contents were prepared, to conduct a parametric study of the fracture energy, such as J-integral value for crack initiation, to assess the effect of LTI content on the fracture property. The study also characterized fracture mechanisms using polarizing-light optical microscopy (POM) and field emission scanning electron microscopy (FE-SEM), to provide

*Received 9 Nov., 2007 (No. 07-0697) [DOI: 10.1299/jmmp.2.455] 
their correlation with the macroscopic fracture behavior.

\section{Experimental}

\subsection{Materials and specimen}

PLA/PCL and PLA/PCL/LTI blends were fabricated using PLA from Shimadzu Corporation (Lacty ${ }^{\circledR}$ \#9030) and PCL from Daicel Chemistry Industries, LTD $\left(\right.$ CelgreenH $\left.7^{\circledR}\right)$ and LTI from Kyowa Co. Ltd., by melt-mixing in a conventional melt-mixer at $180^{\circ} \mathrm{C}$ for $20 \mathrm{~min}$, at a rotor speed of 50rpm. Mixing ratio of PLA and PCL was fixed at $85: 15$ in weight fraction, and LTI content varied from 0.5 to $2 \mathrm{phr}$, at $0.5 \mathrm{phr}$ increment. The blends are denoted as L/C-0.5, L/C-1, L/C-1.5 and L/C-2, respectively, with the number indicating the LTI content. For comparison, PLA/PCL without any LTI was also prepared, denoted as L/C-0. Single-edge-notch-bend (SENB) specimens were prepared from the plates of the above polymer blends for testing. The geometry of the SENB specimen is shown in Fig.1.

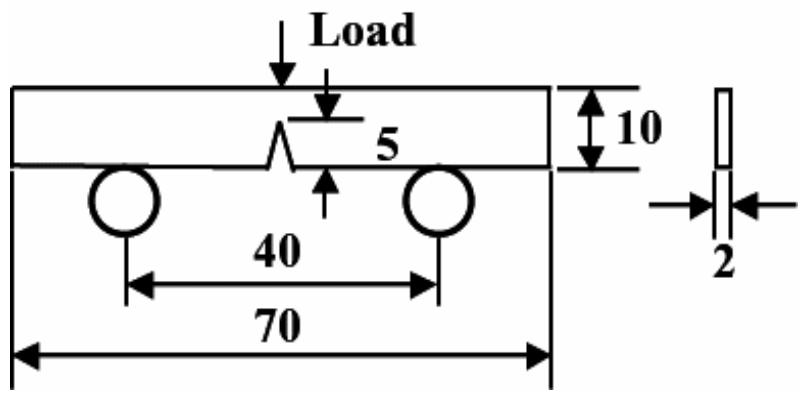

Fig. 1 Geometry of SENB specimen (unit:mm).

\subsection{Mode I fracture test}

Fracture tests in bending mode were conducted using a servo-hydraulic testing machine at a loading rate of $1 \mathrm{~mm} / \mathrm{min}$. Load-displacement curves were recorded to calculate the critical J-integral value in mode $\mathrm{I}, J_{i n}$, at the crack initiation point using the following formula:

$$
J_{\text {in }}=\frac{\eta U_{a b}}{B(W-a)}
$$

where $U_{\text {in }}$ is the critical energy at the crack initiation, $B$ specimen thickness, $W$ specimen width, $a$ crack length and $\eta$ the correction factor, which is equal to 2 for SENB specimen. The critical point for crack initiation was defined as the point at which the specimen rigidity dropped suddenly, as shown in Fig.2.

\subsection{Polarizing-light and scanning electron microscopy}

Samples of thin sections were prepared for POM using the petro-graphic thin-sectioning technique, in regions in front of the crack-tip where a process zone had been developed in the mode I fracture tests. Digital images of the process zone were recorded under the microscope. Crack growth behavior was then tried to be characterized by using the images. Fracture surfaces of the tested specimens were also observed using FE-SEM to understand the effects of LTI on the fracture behavior. In addition, fracture surfaces prepared from samples frozen in liquid nitrogen were examined using FE-SEM to characterize the blend morphology.

\section{Results and Discussion}

\subsection{Blend morphology}

SEM micrographs of cryo-fractured surfaces of these blends are shown in Fig.3. Spherical features shown in these figures are believed to be the PCL-rich phase [9]. The 


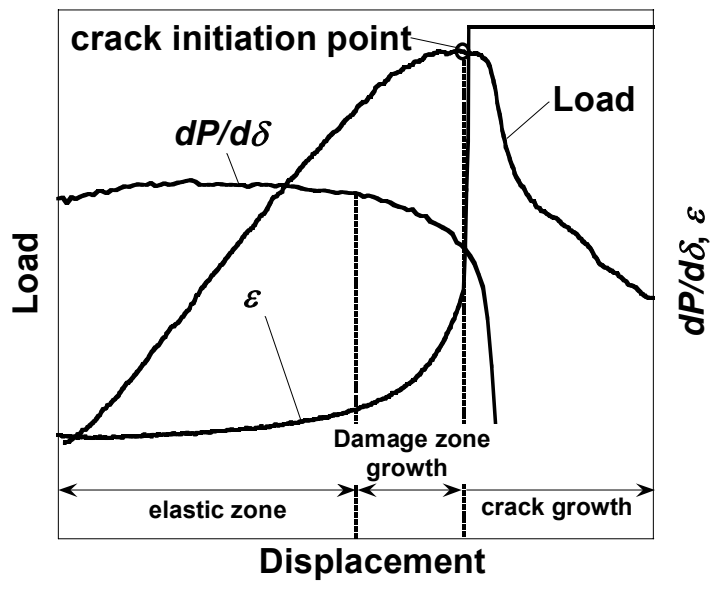

Fig. 2 Typical load-displacement curve and the definition of the crack initiation point

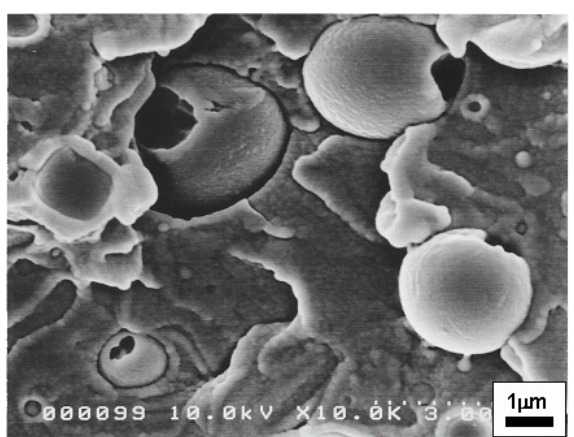

(a) $\mathrm{L} / \mathrm{C}-0$

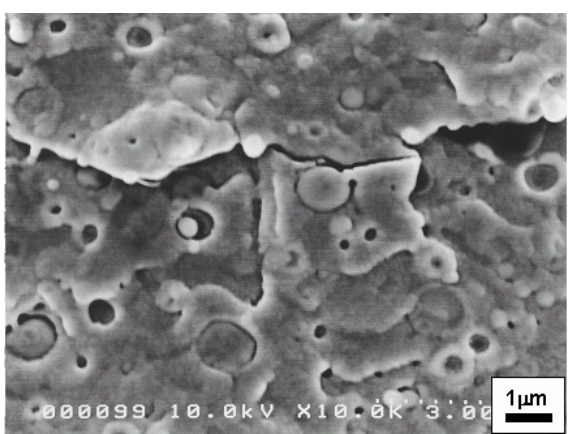

(b) $\mathrm{L} / \mathrm{C}-0.5$

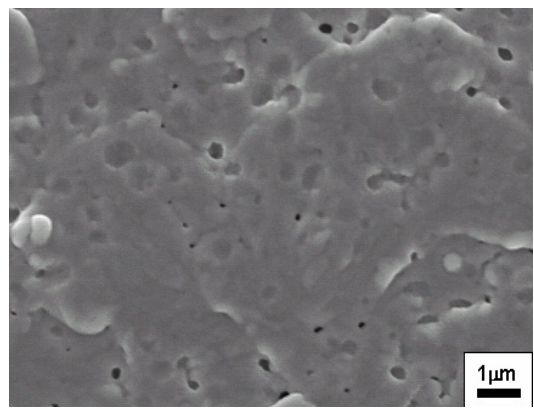

(c) $\mathrm{L} / \mathrm{C}-2$

Fig. 3 SEM micrographs of cryo-fractured PLA/PCL and PLA/PCL/LTI blends.

micrographs in the figure suggest that size of the PCL-rich phase decreases with the increase of the LTI content, to be nearly invisible in Fig.3(c). The trend suggests that the addition of LTI improves miscibility between PLA and PCL dramatically.

\subsection{Critical $J$-integral value at crack initiation}

Dependence of LTI content on $J_{\text {in }}$ is presented in Fig.4. The very left point in the figure suggests that the PLA/PCL blend without LTI is slightly tougher than the pure PLA. However, the fracture energy is greatly improved by the addition of LTI, up to $1.5 \mathrm{phr}$ and saturated by further addition of LTI. Thus, the results clearly suggest that $J_{\text {in }}$ is effectively increased by the addition of LTI to the PLA/PCL blend.

\subsection{Crack growth behavior}

POM micrographs of crack growth behaviors are shown in Fig.5. The craze-like feature 


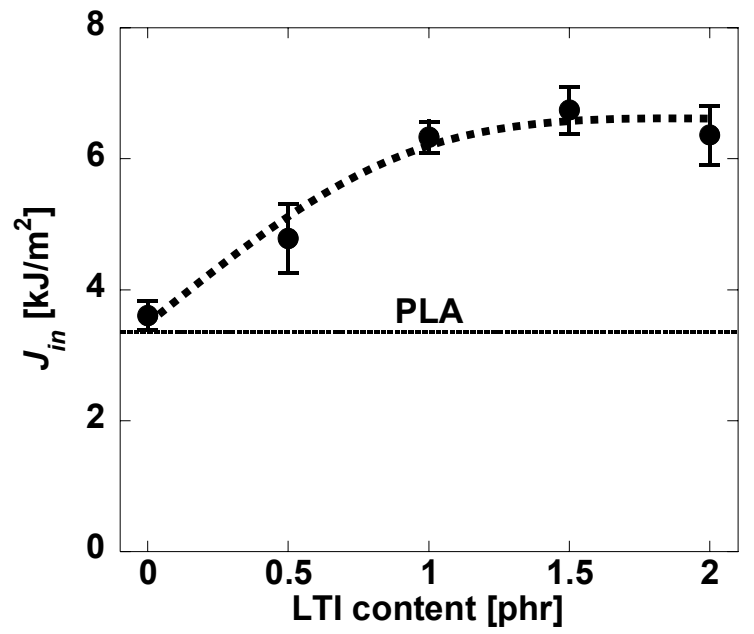

Fig. 4 Dependence of critical J-integral, $J_{i n}$, on the LTI content.

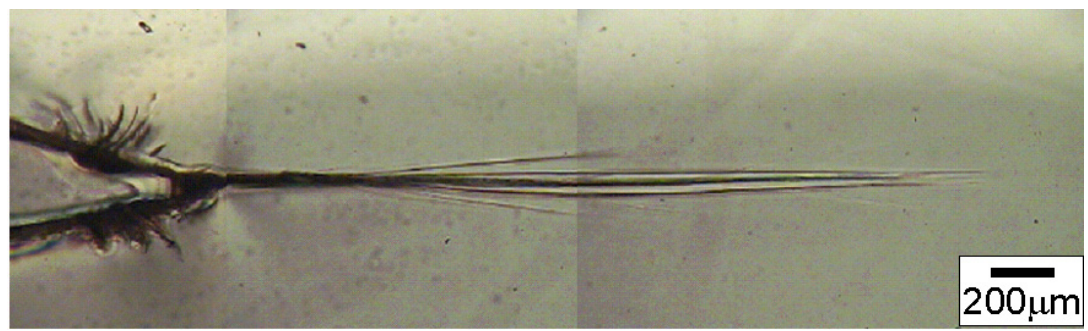

(a) PLA

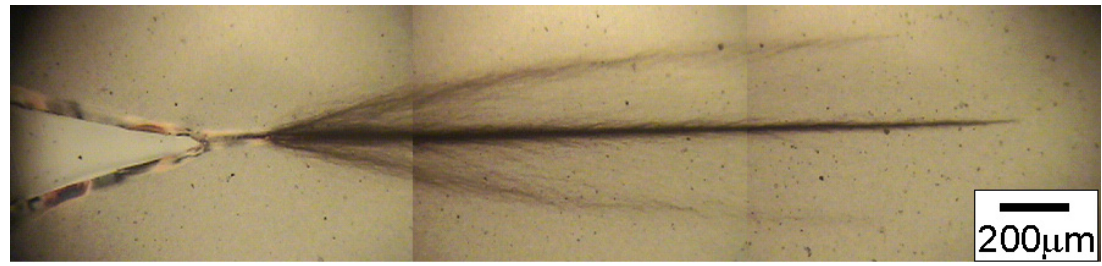

(b) $\mathrm{L} / \mathrm{C}-\mathrm{0}$

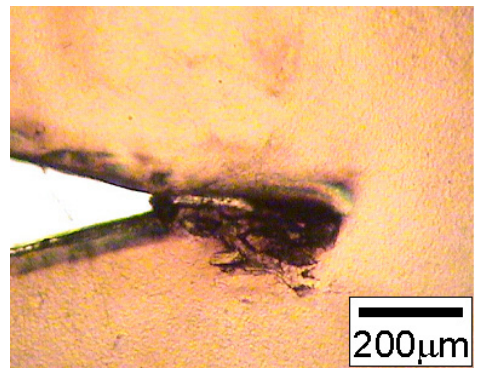

(c) $\mathrm{L} / \mathrm{C}-2$

Fig. 5 POM micrographs of crack growth behaviors.

is clearly seen in front of the crack tip of PLA, Fig.5(a). The damage of craze-like features is broadened by the addition of PCL as shown in Fig.5(b). With the addition of $2 \mathrm{phr}$ LTI, the craze-like feature is no longer visible and a typical pattern of plastic deformation is created as shown in Fig. 5(c). It is therefore believed that the addition of LTI to the PLA/PCL blend has dramatically changed the deformation mechanisms involved in the fracture process. 
Optical micrographs of the fracture surfaces generated by the mode I fracture tests are shown in Fig.6. It is seen that the fracture surface of the pure PLA specimen is flat and smooth, representing the brittle behavior of fracture process. The surface roughness increases with the addition of PCL as shown in Fig.6(b). With the addition of 2phr LTI to PLA/PCL blend, the fracture surface becomes smooth again, however the thickness of the specimen is clearly reduced with the crack growth, from left to right in Fig.6(c). This supports the previous suggestion that the deformation mechanisms were changed by the addition of LTI, possibly from crazing to shear yielding, due to the significant improvement of the blend miscibility.

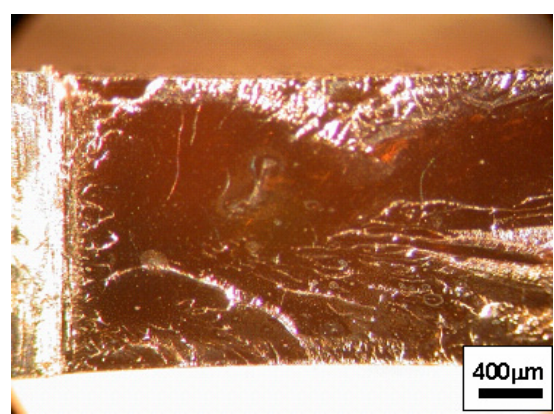

(a) PLA

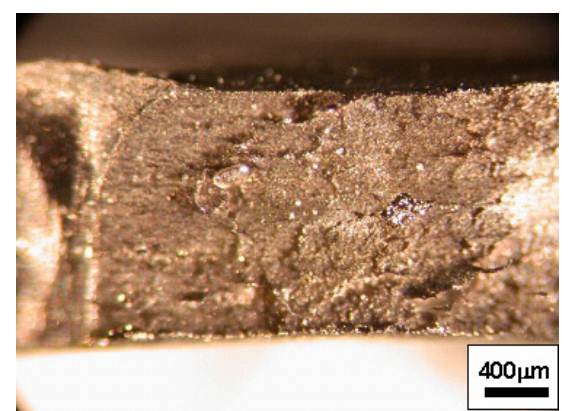

(b) $\mathrm{L} / \mathrm{C}-0$

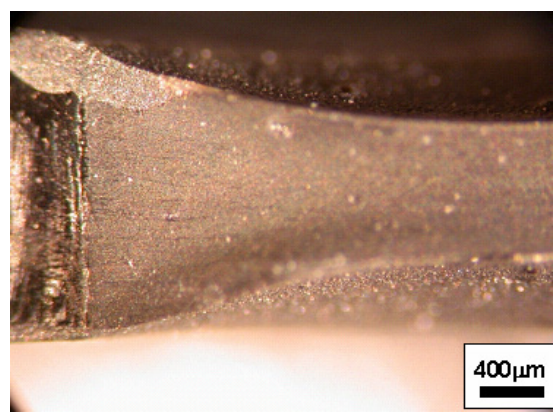

(c) $\mathrm{L} / \mathrm{C}-2$

Fig.6 POM micrographs of fracture surfaces.

FE-SEM micrographs of the fracture surfaces in the vicinity of the notch-tip are shown in Fig.7. The fracture surface of PLA is flat and smooth as shown in Fig.7(a), consistent with the brittle fracture behavior. The surface roughness increases by the addition of PCL, Fig. 7(b), but many voids are also visible, suggesting that the PCL-rich phase has debonded from the surrounding continuous phase during crack growth. These voids are thought to generate local stress concentration in the surrounding regions, but due to the larger size of the damage zone, apparent ductility of the specimen increases, resulting in the slight improvement of measured fracture energy value. Reduction of PCL spherulites formation occurs due to the improvement of miscibility of PLA and PCL and as a result, the amount of voids decreases dramatically. The change of such blend morphology reduces the stress concentration, thus changing the deformation behavior. The change led to the ductile plastic deformation and resulted in the increase of the measured $J_{\text {in }}$ value.

\section{Conclusions}

Effects of LTI addition on the mode I fracture energy and the associated mechanisms of PLA/PCL blend were investigated, with the following conclusions obtained: 


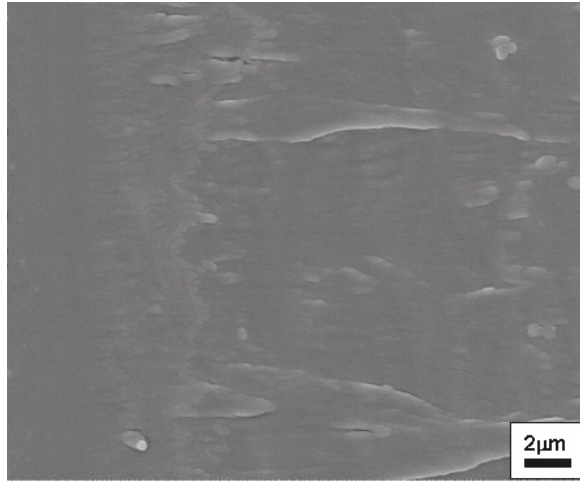

(a) PLA

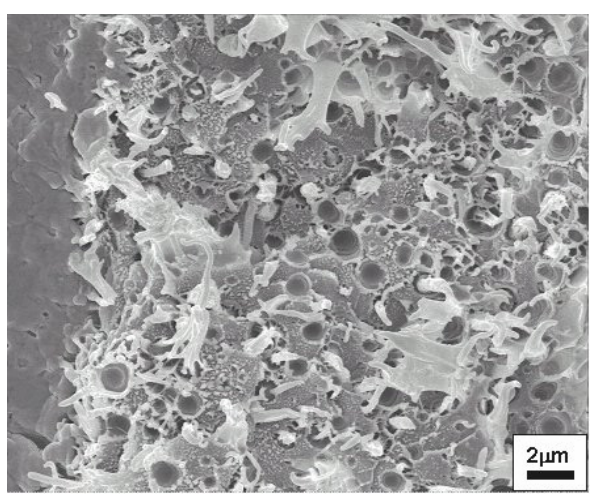

(b) $\mathrm{L} / \mathrm{C}-0$

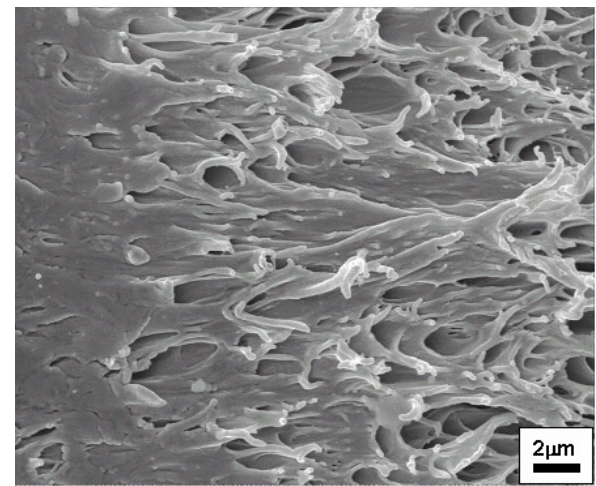

(c) $\mathrm{L} / \mathrm{C}-2$

Fig.7 FE-SEM micrographs of fracture surfaces generated by mode I fracture.

(1) The miscibility of PLA and PCL is dramatically improved by the addition of LTI. As a result, the size of the PCL-rich phase reduced accordingly.

(2) The addition of LTI is effective in improving the fracture energy, in terms of $J_{\text {in }}$, of PLA/PCL blend.

(3) The presence of the discontinuous PCL phase increases the damage sites in the fracture, thus increasing the energy dissipation and resulting in the slight improvement of the fracture energy. However, the addition of LTI to the PLA/PCL blend greatly increases the fracture energy.

\section{References}

(1) Mohanty, A.K., Misra, M., and Hinrichsen, G., Biofibres, biodegradable polymers and biocomposites:An overview, Macromolecular Material Engineering, 276/277 (2000), pp.1-24.

(2) Higashi, S., Tamamoto, T., Nakamura, T., Ikeda, Y., Hyon, S.-H., and Jamshidi, K., Polymer-hydroxyapatite composites for biodegradable bone fillers, Biomaterials, 7 (1986), pp.183-187.

(3) Todo, M., Shinohara, N., and Arakawa, K., Effects of crystallization and loading-rate on the mode I fracture toughness of biodegradable poly (lactic acid), Journal of Materials Science Letters, Vol.21 (2002), pp.1203-1206.

(4) Todo, M., Shinohara, N., and Arakawa, K., Tsuji, H., Effect of Hydrolysis on Fracture Behavior of Poly (L-lactide), Kobunshi Ronbunshu, 60 (2003), pp.644-651.

(5) Park, S.-D., Todo, M., and Arakawa, K., Effect of annealing on the fracture toughness of poly (lactic acid), Journal of Materials Science, Vol.39 (2004), pp.1113-1116. 
(6) Park, S.-D., Todo, M., and Arakawa, K., Effect of Annealing on Fracture Mechanism of Biodegradable Poly (Lactic Acid), Key Engineering Materials, Vol.261/263 (2004), pp.105-110.

(7) Park, S.-D., Todo, M., and Arakawa, K., Effects of Isothermal Crystallization on Fracture Toughness and Crack Growth Behavior of Poly (lactic acid), Journal of Materials Science, Vol.40 (2005), pp.1055-1058.

(8) Tsuji, H., and Ikada, Y., Blends of Aliphatic Polyes-ters. I .Physical Properties and Morphologies of S-olution-Cast Blends from Poly(DL-lactide) and Poly( $\varepsilon$-caprolactone), Journal of Applied Polymer Science, Vol.60 (1996), pp.2367-2375.

(9) Todo, M., Park, S.D., Takayama, T., and Arakawa, K., Fracture micromechanisms of bioabsorbable PLLA/PCL polymer blends, Engineering Fracture Mechanics, Vol.74 (2007), pp.1872-1883.

(10) Wang, L., Ma, W., Gross, R.A., and Mccarthy, S.P., Reactive compatibilization of biodegradable blends of poly(lactic acid) and poly(e-caprolactone), Polymer Degradation and Stability, Vol.59 (1998), pp.161-168.

(11) Hiljanen, M., Varpomaa, P., Sppala, J., and Tormala, P., Modification of poly(L-lactides) by blending:mechanical and hydrolytic behavior, Macromolecular Chemistry and Physics, Vol.197 (1996), pp.1503-1523.

(12) Meredith, J.C., and Amis, E.J., LCST phase separation in biodegradable polymer blends:poly(D,L-1-actide) and poly(e-caprolactone), Macromolecular Chemistry and Physics, Vol.201 (2000), pp.733-739.

(13) Tsuji, H., Yamada, T., Suzuki, M., and Itsuno, S., Blends of aliphatic polyesters.Part. 7.Effects of poly(L-lactide-co- e-caprolactone) on morphology,structure,crystallization, and physical properties of blends of poly(L-lactide) and poly(E-caprolactone), Polymer International, Vol.52 (2003), pp.269-275.

(14) Dell' Erba, R., Groeninckx, G., Maglio, G., Malinconico, M. Migliozzi, A., Immiscible polymer blends of semicrystalline biocompatible components:thermal properties and phase morphology analisis of PLLA/PCL blends, Polymer, Vol.42 (2001), pp.7831-7840.

(15) Harada, M., Hayashi, H., Iida, K., Oda, M., Akita, S., Hirano, K., and Fukuda, H., Blend of Biodegradable Plastics in the presence of Various Addtives, Polymer Preprints in Japan, 52 (2003), 965.

(16) Takayama, T., Todo, M., Arakawa, K., and Tsuji, H., Effect of Additive on Fracture Properties of PLA/PCL Polymer Blend, Transactions of Japan Society for Mechanical Engineers, 72 (2006), pp.713-718.

(17) Takayama, T. and Todo, M., Improvement of impact fracture properties of PLA/PCL polymer blend due to LTI addition, Journal of Materials Science, 41 (2006), pp.4989-4992.

(18) Takayama, T., Todo, M., Tsuji, H., and Arakawa, K., Effect of LTI content on impact fracture property of PLA/PCL/LTI polymer blends, Journal of Materials Science, Vol.41 (2006), pp.6501-6504. 